\title{
Organizational component of pedagogical interaction in ESP teaching in multinational groups in mining region by using hybrid learning
}

\author{
Tatyana Sergeichik ${ }^{1,}$, , and Nin Tuniova ${ }^{1}$ \\ ${ }^{1}$ Kemerovo State University, 650000, 6 Krasnaya st., Kemerovo, Russia
}

\begin{abstract}
Education is traditionally considered a non-profitable, non-commercial branch of the service sector. However, education includes hidden financial, market, social and political resources that ensure the sustainable development of an individual region. Kemerovo State University (KemSU) holds itself out not only as an educational center of the coal region, but also as a center for assembling new-generation specialists capable of supplying labor resources for the main coal and other industries in Russia and other countries. Training takes place in multinational groups, which inevitably leads to the need for pedagogical interaction research in cultural dialogue and intercultural communication. Its organizational component reflects interaction essence and is particularly important. It is a set of educational forms, methods and technologies by which the set goals and objectives are achieved as a result of the interaction and cooperation of all pedagogical interaction subjects, their cooperation and management of the whole process. We believe that the implementation of this component will ensure the sustainable development of human capital in higher education environment to the coal region.
\end{abstract}

\section{Introduction}

In Kuzbass, a coal region, digitalization is becoming the main trend in the region's economy transformation. It affects all industries, including such a conservative sphere as education. This transformation is aimed at solving socio-economic development problems of the coal region while the digital economy formation. KemSU is not just an educational center of the coal region, but acts as a center for training specialists of a new generation for the coal and other industries of Russia and other countries.

Global migration has promoted a steady inflow of foreign students to KemSU for a long time therefore training often happens in multinational groups. Apart from Russian students,

\footnotetext{
*Corresponding author: 1alli8@mail.ru
} 
many international students from 24 countries are provided undergraduate and postgraduate education at the universities of Kuzbass [1]. Groups of students can be either mono-ethnic (Russian students) or multinational (the group includes students from Russia, Uzbekistan and Kyrgyzstan).

The successful training of the future specialists in multiethnic group membership depends on many factors. In particular, significant pedagogical efforts are required to maintain the targeted direction of learning, to coordinate carefully group activity, and coordinate the educational process of the student team, considering its multinational nature. All this actualizes a search for effective forms, means, methods and technologies for successful cooperative learning of students from various ethnic groups.

At the same time, the digital era requires not only new skills from university graduates, but also an advanced approach to organize the training itself. Education no longer presupposes a certain minimum amount of knowledge necessary to transfer from a teacher to student. Currently, teaching involves the interaction of a teacher with a student and a student group, students with each other. Nowadays this interaction should be accompanied with digital technologies.

Pandemic 2020-2021 also contributed to the rapid development of educational technologies. Universities, colleges and schools began to use uncommon teaching methods and forms. In 2020, hundreds of educational institutions around the world were forced to switch to distance learning. This training format assumed the students, due to the coronavirus threat spread, should stay at home and therefore attended online lessons, used electronic educational forms and received tasks by e-mail, in social networks or messengers. In other words, the educational process became completely remote.

Further ongoing unfavorable epidemiologic situation led to the introduction of a new hybrid training format (hybrid learning), in which teachers had to combine both offline and remote classes. Thus, one part of the students (Russian students) studied in classrooms, but the other (foreign students), due to the border closure, joined the classes online and studied at home remotely. This format combined the traditional classroom experience, empirical learning and digital learning materials, multiculturalism and was aimed at obtaining the maximum result for each training goal.

The present study highlights out experience of organizational component of the pedagogical integration model in ESP teaching using digital technologies in hybrid learning at the university.

\section{Materials and methods}

The research on ESP teaching in multinational groups by using hybrid learning has been carried out since 2020. We used the following research methods as testing, interviewing, comparison.

In our study, we understand a pedagogical interaction, carried out in the multiethnic university environment, as a purposeful, productive, equal interpersonal interaction of educational subjects as representatives of various cultures. It implies the development of the ability to carry out professional and business communication in the multicultural environment, as well as the intercultural tolerance formation [2].

The studied model of pedagogical interaction includes interrelated components such as contensive, operational, emotional-motivational, intellectual-cognitive, evaluation-reflexive components.

The operational component reflects the interaction's essence and the combination of educational forms, means, methods and technologies to achieve the set goals as a result of cooperation between subjects of pedagogical interaction [2]. In ESP teaching we intensively engaged students in online tasks to ensure their interaction, exchange 
knowledge, necessary information and ideas. All this contributed to emotional contacts, cooperation, creation, tolerance development, teamwork, etc.

The pandemic led to distance learning and the active use of online learning format. Therefore, we actively implemented training through a variety of e-learning resources, mobile apps and web-resources designated for foreign language teaching and learning. Some of them were analyzed and described from the point of view of their capability and efficiency to conduct foreign language distance learning in multinational student groups. Besides all of them had such features as multimedia, mobility, interactivity and accessibility. Their application in educational environment gave the chance to organize not only independent training, but also group work, creative project activity; and also contributed to the ESP development by an individual path. Mobile applications and web services made it possible to carry out prompt feedback, organize an instant survey and discussion of the results, conduct group assessment and self-control. We achieved a visual presentation and educational content structuring, search for and exchange of educational information, development of critical thinking [3].

The ongoing unfavorable epidemiological situation, the departure of many foreign students to their countries and the closure of borders led to the introduction of a hybrid learning, in which it was necessary to combine lessons simultaneously in the classroom (offline) and distant (online). To organize such a training format, we had to review existing training methods and forms and came to those which could synchronize offline and online formats. To reach and spread all students of the group, we organized a video conference in the Zoom service to communicate with "remote" students, and broadcasted it through a projector to the classroom screen. To encourage active work of all students, we used the definite services to create interactive tasks (LearningApps, H5P, Wordwall) and surveys/tests (Socrative, Quizzis), interactive workbooks and textbooks, demonstrating them on the Zoom screen and the classroom screen. Our goal was to put all students in the "one study plane" to give them the opportunity to see the learning material on the screen during the class and solve tasks altogether, discuss test answers, etc.

Classroom students could join the interactive task through their smartphone and complete it too. It was visible to both classroom students and remote students. Conversely, home students could be "called to the board", and his task completion was also automatically broadcasted on the screen and was visible to everyone.

In general, a hybrid learning lesson requires a classroom screen with a projector or an interactive panel and a teacher's computer (laptop or tablet). Remote students need a PC or a gadget with a video conference application installed and good Internet speed. Classroom students require mobile devices (gadgets) with a good Internet access. The main thing here is the independent student work and their cooperation, while the teacher is the organizer and creator of this learning format. He/she builds not only his/her relations with students, but also their relationship with the digital educational environment, involving them in this process.

Hybrid learning has been the subject of study of many scientists [4-9]. This learning format has some advantages:

- flexibility in schedule, materials, practical tasks, communication with the teacher. Those students who cannot attend classes in person due to distance or health problems are able to continue to study remotely, along with the rest of the students.

- independence from academic flow: introduction of hybrid training format helps to develop self-education skills. Students learn to work with materials personally and do not depend on the academic process, schedule or performance of their fellow students.

- efficient resource allocation: This learning format helps to plan time by allocating meetings and lessons in both virtual and personal formats. The basic principle is to save time, efforts and material and get the maximum efficiency from the meeting. 
- individual approach: depending on the interests, employment, goals and abilities of students, the teacher can vary the material studied and adjust the study speed to the student. Moreover, hybrid learning offers opportunities for additional learning in those areas which interest students most of all.

But there are also some difficulties, such as lack of preparation, lack of knowledge and skills to apply this format by a teacher, lack of necessary equipment, weak Internet signal and other technical difficulties.

\section{Results and discussion}

Since the beginning of the 2020-2021 academic year, we have experienced hybrid learning classes among 4 multinational groups of bachelors of the second year of KemSU (110 students). Where 86 bachelors belonged to the Slavic language group and studied offline, while 24 bachelors belonged to the Turkic language groups and studied distant. According to the European language framework the language competence of all students ranged from A2 to B1. The experiment included the summative and formative assessment phases. During the summative assessment we revealed a level of ESP vocabulary among the Bachelors of the Slavic language group and Bachelors of the Turkic language group. The results are shown in the Table 1.

Table 1. ESP vocabulary level (September 2020).

\begin{tabular}{|c|c|c|}
\hline $\begin{array}{c}\text { ESP vocabulary } \\
\text { level }\end{array}$ & $\begin{array}{c}\text { Bachelors of the Slavic } \\
\text { language group (86 people) }\end{array}$ & $\begin{array}{c}\text { Bachelors of the Turkic } \\
\text { language group (24 people) }\end{array}$ \\
\hline elementary & $21(25 \%)$ & $16(67 \%)$ \\
\hline intermediate & $39(45 \%)$ & $5(21 \%)$ \\
\hline advanced & $26(30 \%)$ & $3(12 \%)$ \\
\hline
\end{tabular}

According to the table 1 the total ESP level of Bachelors of the Slavic language group was rather high ( $30 \%$ advanced and $45 \%$ intermediate levels), which could be explained by a close link to school. All of them had 3 language lessons a week at school and entered professional language smoothly. The total ESP level of Bachelors of the Turkic language group was much lower (around 67\% had an elementary level), which could be explained by a low school level of English and a great difference between Turkic and German language groups.

During the formative assessment we experienced hybrid learning and integrated online learning activities (interactive tasks and quizzes, teacher-led lessons where slides and multimedia could be combined with quiz and poll questions) into the ESP lessons to build a professional thesaurus among all students. To trace ESP progress, we made a comparative study of all students' learning outcomes (topical, midterm and final) and revealed their attitude to the hybrid learning. Moreover, students were encouraged to a collaborative work (to create a student-led reports of some topic mixed with comprehension quizzes and polls). We offered students to alternate between professional topics in English and cultural topics connected with local traditions of each of the multicultural group.

Instant feedback was carried out by Socrative and Quizzes services. To assess their learning outcomes, we used quizzes. They included multiple choice questions and true/false 
statements. After each quiz we initiated a discussion to analyze gaps and mistakes of the studies issue. The comparison of the learning outcomes is presented in Fig.1.

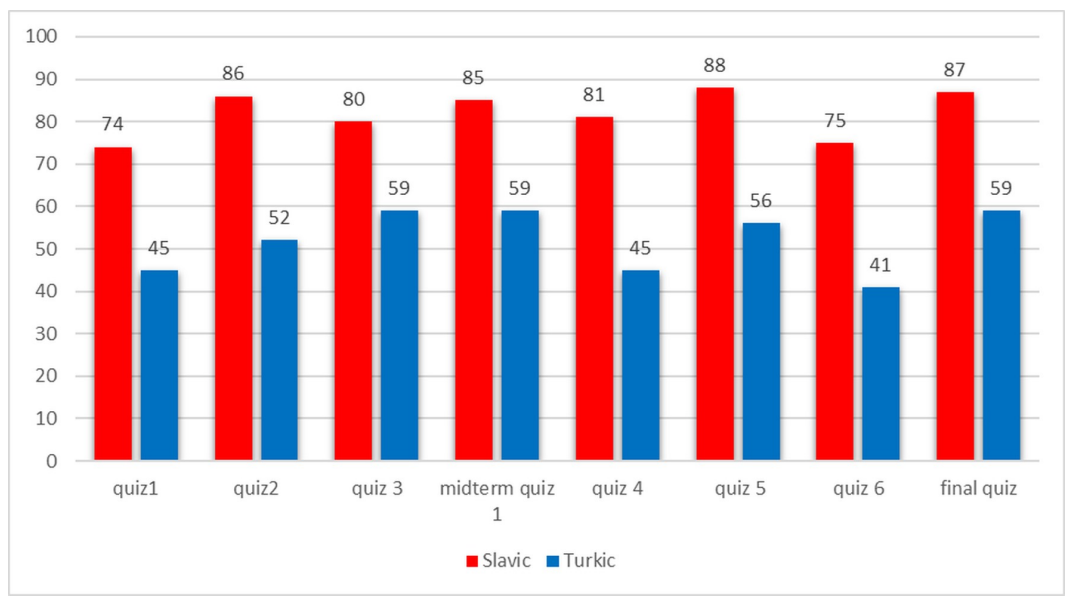

Fig. 1. Average quiz scores of the Bachelors of Slavic and Turkic language groups.

We can see from the Fig. 1 that the levels of professional vocabulary of all student groups experienced an upward trend throughout the academic year though with some fluctuations. The learning outcomes of the Bachelors of Slavic language group outraced the Turkic language. This difference can be explained by the initial low ESP level of Turkic language group. At quiz 1 (September 2020) the ESP level of Slavic language group was higher than ESP level of Turkic language group by $29 \%$. Then it fluctuated at quizzes 2 (October 2020), 3 (November 2020) and midterm quiz (December 2020) but showed a steady growth to $85 \%$. During the whole period the ESP level of Slavic language group demonstrated a gradual rise by $13 \%$ at final quiz (May 2021). As for the ESP level of Turkic language group, it started from a low point of $45 \%$ at quiz 1 (September 2020) but rose to $59 \%$ at quiz 3 (November 2020) and midterm quiz (December 2020). Then we could see some short drops by 14\% at quiz 4 (February 2021) by 15\% and quiz 6 (April 2021) but a coming back upward trend to 59\% at final quiz (May 2021). Overall ESP level of Turkic language group students increased by $14 \%$ for the whole period. Final quiz results demonstrated the learning outcomes of the Bachelors of Slavic language group outraced the Turkic language group almost by a third. Thus, we can conclude that ESP lessons in hybrid learning format (supported with online learning activities) rose the level of professional vocabulary skills of students. Moreover, this progress can be explained also by an active post-task/test discussion and collaboration work (reports).

At last, to discover students' attitude to hybrid learning and online learning activities implemented in ESP lessons we developed the online questionnaire of 8 questions (Google forms) and shared the link with the students via student social network VKontakte. Overall, these lesson transformations were well regarded and enhanced learning motivation by both Bachelors of Slavic and Turkic language groups. They reported about easiness to use online learning tasks, grown learning interest in doing interactive tasks and quizzes with automatic evaluation, collaborative reports and readiness to continue hybrid learning.

\section{Conclusion}

The combination of educational forms and hybrid training technologies and the cooperation of pedagogical interaction subjects in the multinational groups allowed us achieve our goal 
of increasing their ESP level. While ESP teaching we actively engaged students in online learning helping them to interact, cooperate and exchange knowledge, necessary information and ideas. All this also contributed to the establishment of emotional contacts, cooperation, creation, tolerance development, teamwork ability etc.

Updating and transforming the content of teaching methods using digital technologies contributed to the development of a modern digital educational environment at the university. The use of digital materials in ESP teaching ensured students not only learn basic language skills, but also increased their educational motivation, as well as their learning engagement and master their digital skills.

The implementation of educational materials using machine educational technologies, artificial intelligence, the introduction of digital programs, automated testing contributed to the advance of online learning and led to the gradual abandonment of paper-based information media. That was particularly important for students of multiethnic groups, where the development of new learning management systems confirmed that all students had free and fair access to knowledge. The flexibility of ESP teaching at university, achieved through the use of digital tools, was especially important for providing distance learning, which was necessary and inevitable for remote teaching of foreign students, as well as during the pandemic.

The digital transformation of teaching presented by us in hybrid learning allows apply the latest technologies for the transition to a personalized and result-oriented educational process at KemSU flexibly and effectively. The University's digital environment ensures its graduates to get a potential for a sustainable development of Kuzbass as a coal region.

\section{Acknowledgement}

The reported study was funded by RFBR according to the research project № 19-01300805 .

\section{References}

1. O. Greenwald, A. Resenchuk, T. Sergeychick, E3S Web Conf. 105, 04019 (2019)

2. A.Perevalova, World of Science. Pedagogy and Psychology, 1(7), 45 (2019)

3. R. Islamov, O. Greenwald, N. Tunyova, E3S Web Conf. 41, 04041 (2018)

4. C. Demazière, EPJ Web of Conferences, 247, 14001 (2021)

5. S. Arnab, Game Science in Hybrid Learning Spaces, 1, 1-48 (2020)

6. A. Hwang, Journal of Management Education, 4(42), 100 (2018)

7. S. Govindarajan, I-manager's Journal of Education Technology, 7(1), 14-18 (2021)

8. N.E. Sahar, COVID-19 Pandemic and Hybrid Learning System (Willey, New York, 2020)

9. A. Rossydi, Asian EFL Journal, 27(32), 308-319 (2020)

10. N. Dolgova, Ju. Larionova, I. Gubanova, A. Shirokolobova, E3S Web Conf. 174, 04033 (2020) 